\title{
Color segregation and visual search
}

\author{
CLAUS BUNDESEN \\ Copenhagen University, Copenhagen, Denmark \\ and \\ LEIF FLEMMING PEDERSEN \\ Sct. Hans Mental Hospital, Roskilde, Denmark
}

\begin{abstract}
Visual search of color-coded alphanumeric displays was investigated by reaction time methods. The task was to indicate the alphanumeric class of a target item, singled out by appearing in a designated color which varied across trials. Mean reaction time increased with both the number of colors and the number of items in the displays. When same-colored noise items appeared in spatial proximity (organized displays), mean reaction time was a linear function of the number of colors for each level of number of items, and effects of the two factors were additive. For displays constructed by random assignment of colors to individual noise items (scrambled displays), temporal effects of the same factors showed strong interaction. Search times for scrambled displays were predictable from search times for organized displays by use of subjective estimates of the number of phenomenally separate groups of displayed items. The results suggest that visual search for items in the target color consisted in sequentially examining groups of same-colored items, unitized in accordance with Gestalt principles of proximity and similarity, until a unit in the target color was found.
\end{abstract}

Color coding is an efficient method for reducing the time taken to locate a target in a visual scene (Eriksen, 1952, 1953; Hitt, 1961; Williams, 1966). A good example was provided by Green and Anderson (1956). Subjects searched displays of up to 60 items (two-digit numbers) for a specific one. Between trials, the target was varied in color and identity. When the color of the target item was precued, search time showed strong, approximately linear increase with the number of items in the target color. Increase in search time with increase in the number of items in nontarget colors was relatively slight, though not negligible. Later studies by Cahill and Carter (1976; reanalyzed by Carter \& Cahill, 1979), Carter (1982), and Smith (1962, 1963) replicated these results.

The finding that search time increases linearly with the number of items in the target color suggests that-under varied mapping conditions (cf. Schneider \& Shiffrin, 1977)-items in the target color are examined sequentially. The source of the latency effect of items in nontarget colors is less clear. Some authors (e.g., Broadbent, 1971, p. 181; Shiffrin \& Schneider, 1977) have proposed that these

This research was conducted at Copenhagen University. Jørgen Døssing created our software stimulus characters on a color display system available at the Institute of Datalogy. Jørgen Rathje provided technical support at the Psychological Laboratory. Axel Larsen took part in many phases of the work. Requests for reprints should be sent to Claus Bundesen, Psychological Laboratory, Copenhagen University, Njalsgade 90, DK2300 Copenhagen S., Denmark. items too are individually examined, but rapidly rejected on the basis of their color. Others (e.g., Cahill \& Carter, 1976; Farmer \& Taylor, 1980) have invoked the notion of preattentive grouping operations (cf. Banks \& Prinzmetal, 1976; Kahneman, 1973; Neisser, 1967; Prinzmetal \& Banks, 1977), suggesting that groups of items, formed by similarity in color, may be rejected as units.

Extant data on visual search (see Farmer \& Taylor, 1980) and related data from partial report paradigms (Fryklund, 1975; Kahneman \& Henik, 1977, 1981) do suggest that grouping of noise items by color is important, but the way such grouping is utilized in the search process has not been established. The present experiment was designed to clarify this issue. We explored the hypothesis that when target color is varied between trials, visual search for items in the target color consists of sequentially examining nonoverlapping groups of same-colored items, formed in accordance with Gestalt principles of proximity, similarity, and the like (cf. Wertheimer, 1923), until a group has been found that matches the target color.

Our subjects were instructed to indicate as quickly as possible whether a target, singled out by appearing in a prespecified color, was a letter or a digit. The target could appear in any position within an imaginary $5 \times 5$ matrix containing from 0 up to 24 noise items (letters and digits) representing up to five different nontarget colors. Disregarding displays with target alone, number of items and number of colors were varied orthogonally. In organized 
displays, same-colored noise items appeared in spatial proximity; scrambled displays were constructed without this constraint.

Perceptual grouping of noise items by color should be facilitated by having same-colored noise items appear in spatial proximity. We conjectured that with organized displays, visual search for the targetcolored item would occur by sequentially examining a number of groups, each consisting of all items in one of the colors, until finding a (singleton) group consisting of the target-colored item. If the time taken to test whether a group has the target color is a constant, the time taken to find the target should increase in direct proportion to the number of colors in the display, regardless of the number of items. Once located, however, the target should be categorized as a letter or a digit. Considering data on effects of noise items in nonsearch tasks (e.g., Eriksen \& Eriksen, 1974; Eriksen, Hamlin, \& Daye, 1973; Eriksen \& Schultz, 1979; Harms \& Bundesen, 1983; Taylor, 1977), we expected that the time required to determine whether the target was a letter or a digit would increase with the number (density) of items in the display, but not with the number of colors. For organized displays, then, mean reaction time should be linearly related to the number of colors in a display, the slope constant should be half the time taken to check the color of a group, and the intercept should increase with the number of items in the display.

Predictions for performance with scrambled displays were less specific. Since items were colored without regard to spatial proximity, perceptual groups of same-colored items should, on the average, be smaller in size and greater in number. The number of groups to be separately tested for color being greater, search time should be longer than for organized displays. We hoped to provide a basis for a more complete analysis by obtaining subjective estimates of the number of separate groups of items in each of the scrambled displays.

\section{METHOD}

\section{Stimulus Displays}

The stimulus material comprised 1,080 slides, each of which displayed a number of alphanumeric characters positioned within an imaginary $5 \times 5$ matrix (see Figure 1). The slides were photographed from displays generated by computer on a Ramtek GX-100B color screen using a specially designed character set. Each character was constructed from square cells within a rectangular grid 8 cells wide $\times 12$ cells high. The average number of cells per character was 48 . Horizontal spacing between grids for characters in successive columns of the $5 \times 5$ matrix equaled six cells in size; vertical spacing between grids for characters in successive rows equaled two cells. The characters were white, black, purple (with an approximate Munsell notation of 2.5RP 5/10, measured under the experimental viewing conditions), orange $(2.5 Y R 7 / 10)$, green (5GY $8.5 / 10)$, or blue $(10 \mathrm{~B} 6 / 8)$, and the background was bluish gray $(2.5 \mathrm{~B} 5 / 6)$. The colors were chosen with the aim of achieving high discriminability.

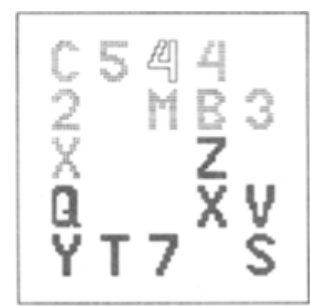

ORGANIZED

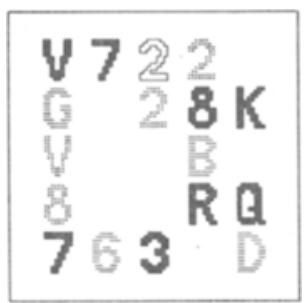

SCRAMBLED
Figure 1. Two stimulus displays. Difference in color between items is represented by difference in texture. Left panel: An organized display with 17 items (one target plus 16 noise items) in four different colors. Right panel: $A$ scrambled display partnering the organized one.

A display contained one character (the target item) in a designated color (the target color) and a varying number of characters (noise items) in other colors. Let the number of displayed items and the number of displayed colors be $N$ and $n_{c}$, respectively. For the 180 no-noise (i.e., target alone) displays, $N=n_{c}=1$. For displays with noise items, $N$ could be 9,17 , or 25 ; for each value of $N, n_{c}$ could be 2,4 , or 6 ; and when $n_{c}$ was 4 or 6 , displays could be either organized or scrambled, as explained below. For $n_{c}$ equal to 2 , there were 60 displays for each value of $\mathrm{N}$, and for $\mathrm{n}_{\mathrm{c}}$ equal to 4 or 6 , each display type (organized vs. scrambled) was represented by 60 displays for each value of $\mathbf{N}$. Each set of 60 displays comprised 30 letter-target displays (i.e., displays in which the target was a letter) and 30 digit-target displays. Further constraints are given below. (Similar constraints applied to the set of 180 no-noise displays.)

Locations. Across a set of 60 displays with given $\mathrm{N}, \mathrm{n}_{\mathrm{c}}$, and display type (when relevant), each cell of the $5 \times 5$ stimulus matrix was occupied at least once by a letter target and once by a digit target. Each of 10 particular cells, distributed over the matrix with 2 in each row and 2 in each column, was occupied thrice by a target, while other cells were occupied twice by a target. For any display, however, the $\mathrm{N}-1$ cells occupied by noise items were selected at random.

Items. Nine digits ( 0 excluded) and 20 consonants (including $Y$, but not $W$ ) were used as target and noise items. Noise items were chosen independently such that the two alphanumeric classes were equiprobable. Choices among different digits and among different consonants were always random with replacement.

Colors. Each of the six item colors was used as target color in 5 letter-target and 5 digit-target displays within the set of 60 displays representing a given combination of $\mathrm{N}, \mathrm{n}_{\mathrm{c}}$, and display type. Consider the set of 10 displays with a given target color. If $\mathrm{n}_{\mathrm{c}}$ was 2 , each of the five possible nontarget colors was represented once in a letter-target and once in a digit-target display. If $n_{c}$ was 4 , each of the $\left(\begin{array}{l}3 \\ 3\end{array}\right)=10$ possible combinations of three nontarget colors was represented in one of the 10 displays. If $\mathrm{n}_{\mathrm{c}}$ was 6 , every nontarget color was, of course, used in each display.

Assigning colors to items. Given $n_{c}-1$ nontarget colors and $\mathrm{N}-1$ noise items in selected locations within the stimulus matrix, coloring of items was completely specified if $n_{c}$ was 1 or 2 . For $\mathrm{n}_{\mathrm{c}}$ equal to 4 or 6 , organized displays were constructed by the following procedure for assigning colors to individual noise items. A subset of $n_{c}-1$ cells, called kernels, were drawn randomly from the set of $\mathrm{N}-1$ cells occupied by noise items: one kernel for each of the nontarget colors. The kernels were rankordered at random. Any noise item was then assigned the color associated with the nearest kernel, ties being broken in favor of the highest ranking kernel. The distance between a noise item in row $\mathrm{i}$ and column $\mathrm{j}$ of the stimulus matrix and a kernel in row $k$ and column 1 was simply measured by $\sqrt{(i-k)^{2}+(j-l)^{2}}$. 
For each organized display, a scrambled partner was constructed with the same type of target (letter vs. digit), the same target color and target location, the same locations occupied by noise items, and the same number of items in each of the $\mathrm{n}_{\mathrm{c}}-1$ nontarget colors. Except for the constraint on the number of items in each color, however, the scrambled display was made by random assignment of colors to individual noise items.

\section{Blocking}

The set of 1,080 stimulus displays was partitioned into two main blocks of 540 displays, Blocks $A$ and $B$. For $n_{c}$ equal to 4 or 6, Block $A$ contained the organized displays and Block B contained the scrambled ones. For $n_{c}$ equal to 1 or 2 , procedures for constructing organized and scrambled displays were formally equivalent. For each value of $N$, one half of the displays constructed with $n_{c}$ at 1 or 2 was assigned to Block $A$ and the remaining half was assigned to Block $B$, the two halves being closely matched with respect to target types (letters vs. digits), target colors and locations, and nontarget colors.

From each main block, 30 consecutive subblocks of 18 displays were formed such that (1) target color was kept constant within but varied (counterbalanced) between subblocks, (2) the number of displays representing a given combination of $\mathbf{N}$ and $n_{c}$ was the same in any subblock, and (3) no pair of successive displays contained the target in the same location. The ordering of the 540 displays was otherwise random, and a new randomization was made for each experimental session.

\section{Procedure}

The subject was seated about $2 \mathrm{~m}$ in front of a screen on which the projections of the slides subtended approximately $19 \mathrm{deg}$ of visual angle horizontally and $16 \mathrm{deg}$ vertically. A single character grid subtended $.69 \mathrm{deg}$ in width and $1.04 \mathrm{deg}$ in height. Center-to-center distance between adjacent character grids in the same row or in the same column of the $5 \times 5$ stimulus matrix was $1.21 \mathrm{deg}$. The display was viewed binocularly with free fixation. During projection of a slide, the pupils of the subject received an illuminance of about $4 \mathrm{~lx}$ from the stimulus field (i.e., the projected slide) and $3 \mathrm{~lx}$ from the surrounding field.

Search task. Subjects participated individually in one practice and three experimental sessions with the search task. Each session comprised a run through Blocks $A$ and $B$ with a pause of about $15 \mathrm{~min}$ between main blocks and a 1-min break after each set of three consecutive subblocks of 18 trials. Order of main blocks was systematically varied across subjects and sessions.

Stimulus presentation and data collection were automated by a PDP-11 computer. Prior to each block of 18 trials, the target color used in the block was shown on a separate slide. The trials began when the subject pressed a starting key which made the first stimulus display in the block appear with a latency of 2,000 msec. The subject was instructed to decide "as quickly as possible" whether the target-colored item was a letter or a digit. The decision was indicated by pressing a leftor a right-hand button, and reaction time was measured in milliseconds from stimulus onset. Stimulus exposure terminated with a latency of $200 \mathrm{msec}$ when one of the response buttons was pressed, and the next stimulus display was projected after a fixed intertrial interval of $2,000 \mathrm{msec}$ unless the subject opted for a pause by pressing a halting key. Feedback about speed or accuracy was not provided. For each subject, mapping of target type (letter vs. digit) to response hand (left vs. right) was the same throughout the experiment.

Phenomenal task. In a later session, the subjects were individually presented with the 540 displays in Block $B$ and requested to estimate the number of phenomenally separate nonoverlapping groups of items in each display. The task was further specified as follows. First, a sample of displays from Block A was shown and the subject was informed that, in the experimenter's opinion, the number of phenomenally separate groups of items in the Block A displays equaled the number of different colors. Second, the experimenter suggested that, in Block B displays, the number of phenomenally separate groups of items might differ from the number of different colors. The subject was then encouraged to arrive at numerical estimates by counting as carefully as possible. The numerical responses were given orally and written down by the experimenter without feedback to the subject.

\section{Subjects}

All subjects were students or members of the staff at Copenhagen University, and all had normal or corrected-to-normal visual acuity and normal color vision. They were paid by the hour. Five subjects participated in the search task. After completion of the search task, two of the subjects left our pool. The remaining three and two new subjects served as observers in the phenomenal task.

\section{RESULTS}

\section{Search Data}

Reactions slower than $1,500 \mathrm{msec}$ were not analyzed, which eliminated 36 of 16,200 trials. All analyses of reaction times were based on correct reactions. Individual error rates ranged between .041 and .125 , but data for individual subjects and sessions were similar in structure.

Block A. Results from Block A (organized displays) are summarized in Table 1 and Figure 2. Mean reaction times increased systematically with both the number of colors and the number of items in the displays, and the effects of the two factors were approximately additive. Averaged over displays with 9,17 , or 25 items, mean reaction time was a linear function of the number of displayed colors with a slope constant of $12.3 \mathrm{msec}$ per color. A minimum chi-square fit of three parallel lines to mean reaction time as a function of number of colors with number of items $(9,17$, or 25$)$ as the parameter seemed satisfactory (see Figure 2$)\left[\chi^{2}(5)=\right.$ $8.85, \mathrm{p}>.10]$.

Reaction time data for displays with noise items in Block A were subjected to a two-factor (number of colors $\times$ number of items) repeated-measures ANOVA. Under the conservative GreenhouseGeisser test procedure (cf. Winer, 1971, p. 523),

Table 1

Mean Reaction Time (in Milliseconds) and Error Rate (in

Percent) as Functions of Number of Colors and Number of Items in Block A (Organized Displays)

\begin{tabular}{|c|c|c|c|c|c|c|c|c|}
\hline \multirow{3}{*}{$\begin{array}{l}\text { Number } \\
\text { of Items }\end{array}$} & \multicolumn{8}{|c|}{ Number of Colors } \\
\hline & \multicolumn{4}{|c|}{ Reaction Time } & \multicolumn{4}{|c|}{ Error Rate } \\
\hline & 1 & 2 & 4 & 6 & 1 & 2 & 4 & 6 \\
\hline 1 & 482 & & & & 4.0 & & & \\
\hline $\begin{array}{l}1+8 \\
1+16 \\
1+24\end{array}$ & & $\begin{array}{l}546 \\
561 \\
574\end{array}$ & $\begin{array}{l}560 \\
595 \\
601\end{array}$ & $\begin{array}{l}595 \\
615 \\
619\end{array}$ & & $\begin{array}{r}9.1 \\
6.0 \\
10.9\end{array}$ & $\begin{array}{r}8.5 \\
10.1 \\
10.0\end{array}$ & $\begin{array}{r}8.8 \\
10.0 \\
10.3\end{array}$ \\
\hline
\end{tabular}

Note-Reaction times are for correct responses. Data are group results for five subjects. 


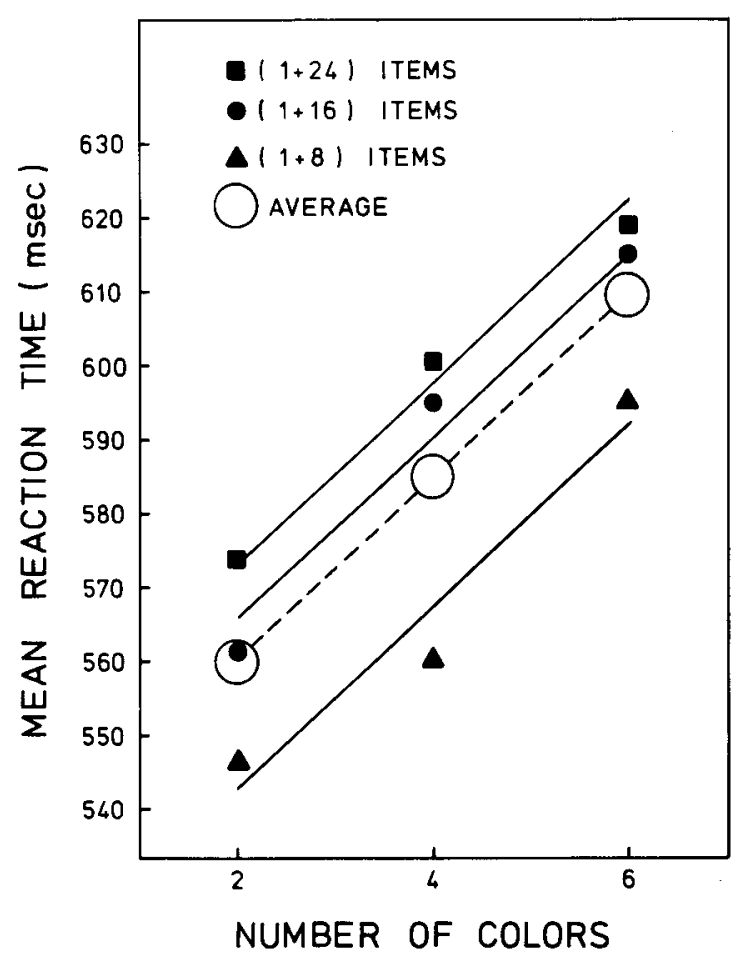

Figure 2. Mean reaction time for displays with noise items in Block A (organized displays) as a function of number of colors with number of items (target plus noise) as a parameter. Data for the three levels of the parameter are fitted by three parallel solid lines. Data averaged across levels of the parameter are fitted by a broken line.

the main effects of number of colors $[F(1,4)=45.3$, $\mathrm{p}<.005]$ and number of items $[F(1,4)=15.3$, $\mathrm{p}<.05]$ were both significant, but the interaction between number of colors and number of items was not $[F(1,4)=3.65, p>.10]$. The effect of number of colors showed a highly significant linear trend $[F(1,4)=90.6, p<.001]$, but no significant quadratic trend $(F<1)$.

Error data were less informative. The correlation between error rates and reaction times in Block $A$ was positive $(r=.82)$, but a two-factor (number of colors $\times$ number of items) repeated-measures ANOVA performed on arcsin transformed error data detected no significant effects.

Block B. Results from Block B (scrambled displays) are shown in Table 2 and Figure 3. Mean reaction times increased with both the number of colors and the number of items in the displays, and the higher the level of one of the factors, the stronger was the effect of the other one. Reliability of these findings was established by a two-factor (number of colors $\times$ number of items) repeated-measures ANOVA on reaction time data for displays with noise items. Under the Greenhouse-Geisser procedure, the effects of number of colors $[F(1,4)=$
97.4, $\mathrm{p}<.001]$, number of items $[F(1,4)=77.2$, $\mathrm{p}<.001]$, and number of colors $\times$ number of items $[F(1,4)=25.4, p<.01]$ were all significant.

Table 2

Mean Reaction Time (in Milliseconds) and Error Rate (in Percent) as Functions of Number of Colors and Number of Items in Block B (Scrambled Displays)

\begin{tabular}{|c|c|c|c|c|c|c|c|c|}
\hline \multirow{3}{*}{$\begin{array}{l}\text { Number } \\
\text { of Items }\end{array}$} & \multicolumn{8}{|c|}{ Number of Colors } \\
\hline & \multicolumn{4}{|c|}{ Reaction Time } & \multicolumn{4}{|c|}{ Error Rate } \\
\hline & 1 & 2 & 4 & 6 & 1 & 2 & 4 & 6 \\
\hline 1 & 495 & & & & 5.6 & & & \\
\hline $\begin{array}{l}1+8 \\
1+16 \\
1+24\end{array}$ & & $\begin{array}{l}563 \\
566 \\
569\end{array}$ & $\begin{array}{l}589 \\
617 \\
634\end{array}$ & $\begin{array}{l}605 \\
656 \\
673\end{array}$ & & $\begin{array}{l}7.6 \\
4.0 \\
6.2\end{array}$ & $\begin{array}{r}13.2 \\
8.7 \\
7.7\end{array}$ & $\begin{array}{l}9.6 \\
7.7 \\
8.9\end{array}$ \\
\hline
\end{tabular}

Note-Reaction times are for correct responses. Data are group results for five subjects.

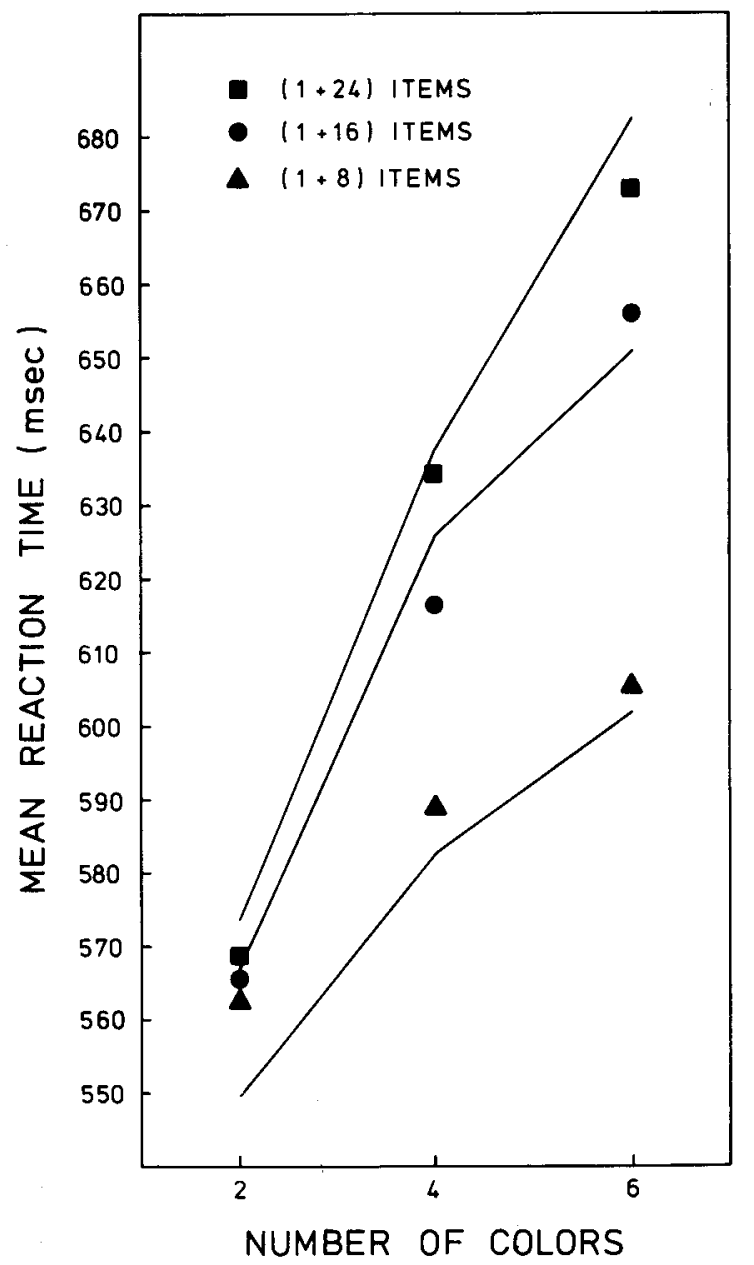

Figure 3. Mean reaction time for displays with noise items in Block B (scrambled displays) as a function of number of colors with number of items (target plus noise) as a parameter. Unmarked points connected by straight lines represent a theoretical fit to the data. 
Correlation between error rates and reaction times in Block B was .40. By two-factor (number of colors $\times$ number of items) repeated-measures ANOVA on arcsin transformed error rates, only the effect of number of colors reached significance $[F(1,4)=10.2, p<.05]$.

Comparison between blocks. A three-factor (blocks $\times$ number of colors $\times$ number of items) repeated-measures ANOVA on reaction times for displays with noise items established that the two blocks differed with respect to grand mean (smaller in Block A), effect of number of colors (weaker in Block A), and interaction between number of colors and number of items (negligible in Block A). Thus, under the Greenhouse-Geisser procedure, there were: significant effects of blocks $[F(1,4)=$ $20.4, p<.05]$, number of colors $[F(1,4)=75.3$, $\mathrm{p}<.001]$, and number of items $[\mathrm{F}(1,4)=46.3$, $\mathrm{p}<.005$; significant two-way interactions between blocks and number of colors $[F(1,4)=55.2$, $p<$ $.005]$ and between number of colors and number of items $[F(1,4)=9.82, p<.05]$, but not between blocks and number of items $[F(1,4)=1.27, p>.10]$; and a significant three-way interaction between blocks, number of colors, and number of items $[\mathrm{F}(1,4)=33.4, \mathrm{p}<.005]$.

By three-factor (blocks $\times$ number of colors $\times$ number of items) repeated-measures ANOVA on arcsin transformed error rates, effects of blocks $[F(1,4)=8.02, p<.05]$ and number of colors $[F(1,4)=8.31, p<.05]$ were significant.

\section{Phenomenal Data}

Table 3 shows mean estimated number of phenomenally separate nonoverlapping groups of items as a function of number of colors and number of items in Block B. The estimated number of separate groups of items was never lower than the number of colors; in most cases it was considerably higher. For any number of items, the estimate increased with the number of colors, and the greater the number of items, the stronger was the increase with number of colors. The pattern of estimates (in Table 3) resembled the pattern of reaction times (in

Table 3

Mean Estimated Number of Separate Groups of Items as a Function of Number of Colors and Number of Items in Block B (Scrambled Displays)

\begin{tabular}{lccrr}
\hline \multirow{2}{*}{$\begin{array}{l}\text { Number } \\
\text { of Items }\end{array}$} & \multicolumn{4}{c}{ Number of Colors } \\
\cline { 2 - 5 } & 1 & 2 & 4 & \multicolumn{1}{c}{6} \\
\hline 1 & 1.0 & & & \\
$1+8$ & & 3.3 & 6.6 & 7.8 \\
$1+16$ & & 2.1 & 9.3 & 11.4 \\
$1+24$ & & 2.0 & 10.0 & 15.1 \\
\hline
\end{tabular}

Note-Data are group results for five subjects.
Table 2) for the same displays; by correlation across the 10 combinations of number of colors and number of items, $r=.94$.

A two-factor (number of colors $\times$ number of items) repeated-measures ANOVA on estimated number of separate groups in Block B displays with noise items indicated that the main effects of both number of colors $[F(1,4)=368.7, p<.001]$ and number of items $[F(1,4)=94.8, p<.001]$ and the interaction of number of colors with number of items $[F(1,4)=110.4, p<.001]$ were highly significant.

\section{DISCUSSION}

Consider the hypothesis that visual search for items in the target color consisted of sequentially examining groups of same-colored items until a group was found that matched the target color. If the search space for a display with $N$ items and $n_{c}$ colors contained $\mathrm{n}$ units (i.e., $\mathrm{n}$ functionally separate groups of same-colored items), the expectation of the number of units tested in order to find the target by sampling without replacement was $(n+1) / 2$. Accordingly, if the time taken to test the color of a unit was a constant, say, $2 a$, the expected time taken by color testing was $a(n+1)$. The residual latency of the reaction process should depend upon the number of items and not upon the number of colors. If the expected residual was $b_{N}$, expected reaction time should be

$$
R T=a(n+1)+b_{N} .
$$

We predicted that, in Block A (organized displays), each unit in the search space would consist of all items in one of the colors such that $n$ equaled $\mathrm{n}_{\mathrm{c}}$. The results accorded with this prediction. To a good approximation, mean reaction time was a linear function of $n_{c}$ for each value of $N$, and effects of $\mathrm{N}$ and $\mathrm{n}_{\mathrm{c}}$ were additive. Minimum chi-square estimates of $b_{\mathrm{N}}$, for $\mathrm{N}$ equal to 9,17 , and 25 , were 504,530 , and $537 \mathrm{msec}$, respectively. The estimate for a was $12.3 \mathrm{msec}$, corresponding to a search rate of about 25 msec per unit.

To fit the results from Block B (scrambled displays) by Equation 1, values of $n$ must be specified for displays in this block. The expected number of functionally separate groups of items (n) should be related to the obtained estimates of the number of phenomenally separate groups $\left(n_{s}\right)$. The relationship was modeled as follows. (1) The phenomenal groups partitioned the set of items in a display such that different-colored items always belonged to different groups. (This assumption was substantiated by subjective reports.) (2) The functional groups satisfied the same condition. (3) Functional 
groups were either individual phenomenal groups or unions of phenomenal groups. (4) The expected number of functional groups in a given color increased with the number of phenomenal groups in that color; the rate of increase was a constant $p$. The stated assumptions imply that ${ }^{1}$

$$
\mathrm{n}=\mathrm{n}_{\mathrm{c}}+\mathrm{p}\left(\mathrm{n}_{\mathrm{s}}-\mathrm{n}_{\mathrm{c}}\right) .
$$

Given the estimates of $a$ and $b_{N}$ (for $N=9,17$, 25) from Block $A$ and the observed values of $n_{s}$ shown in Table 3, Equations 1 and 2 predict a set of mean reaction times for Block $B$ corresponding to the factorial combinations of number of colors $(2,4$, or 6$) \times$ number of items $(9,17$, or 25$)$, once parameter $p$ is specified. An estimate of .54 for $p$ was determined from the grand mean of the observed reaction times in Block B depicted in Figure 3. The predicted mean reaction times for Block $B$ are represented in Figure 3 as unmarked points connected by straight lines. Considering that only one parameter was estimated from the reaction times in Block B, the fit is quite good, accounting for $96.5 \%$ of the variance. The model seems to capture the structure of the data.

\section{Generality}

Taken together, the results from Blocks $A$ and $B$ lend considerable support to the hypothesis that visual search for items in the target color consisted of sequentially examining units formed from samecolored items by Gestalt principles of proximity and similarity, until a unit in the target color was located. We suggest two limitations on the generality of our findings. First, the colors we used were highly discriminable. With less discriminable colors (cf. Farmer \& Taylor, 1980), grouping of items by similarity in color would be less pronounced and harder to manipulate, and, eventually, our concept of same-colored items would be too crude.

Second, target color varied between short blocks of trials. If target color were kept constant across trials, processing might change from "controlled search" to "automatic detection" of units in the target color (cf., e.g., Bundesen, 1982; LaBerge, 1975, 1981; Schneider \& Shiffrin, 1977; Shiffrin, Dumais, \& Schneider, 1981). There is some support for this conjecture. Carter (1982, Experiment 2) reported little effect of noise items in a color that was easily discriminable from the target's; $n_{c}$ was either one or two, and the target color was consistently the same. Similarly, in related experiments with consistent-mapping designs, Treisman and her associates (Treisman, 1982; Treisman \& Gelade, 1980; Treisman, Sykes, \& Gelade, 1977) found little effect of number and spatial arrangement of noise elements on the time taken to detect the presence of a (highly discriminable) target color.
Treisman and her associates accounted for their results by the assumption that simple features such as color are detected automatically, without attention, and in parallel across the visual field (regardless of whether the mapping of stimuli to responses is consistent or varied). Our findings with a variedmapping design present a challenge to this account.

\section{Further Perspectives}

A visual scene may be analyzed at different levels, and the strategy for processing described in this article is multilevel in nature: Groups of items were tested for color, and individual items were tested for alphanumeric class. With displays containing several items in the target color, as in the Green and Anderson (1956) paradigm, the search process itself should be overtly hierarchic: first among groups, then among items within a group. If the set of target-colored items formed a number of separate groups, back-ups from the item to the group level might be expected. An experimental analysis of the time consumed by shifting between levels should further understanding of visual search of complex scenes.

\section{REFERENCES}

Banks, W. P., \& Prinzmetal, W. Configurational effects in visual information processing. Perception \& Psychophysics, 1976, 19, 361-367.

Broadbent, D. A. Decision and stress. New York: Academic Press, 1971.

BundeSEN, C. Item recognition with automatized performance. Scandinavian Journal of Psychology, 1982, 23, 173-192.

Cahill, M.-C., \& Carter, R. C. Color code size for searching displays of different density. Human Factors, 1976, 18, 273-280.

CARTER, R. C. Visual search with color. Journal of Experimental Psychology: Human Perception and Performance, 1982, 8, 127-136.

Carter, R. C., \& Cahill, M.-C. Regression models of search time for color-coded information displays. Human Factors, $1979,21,293-302$.

Eriksen, C. W. Location of objects in a visual display as a function of the number of dimensions on which the objects differ. Journal of Experimental Psychology, 1952, 44, 56-60.

Eriksen, C. W. Object location in a complex perceptual field. Journal of Experimental Psychology, 1953, 45, 126-132.

Eriksen, B. A., \& Eriksen, C. W. Effects of noise letters upon the identification of a target letter in a nonsearch task. Perception \& Psychophysics, 1974, 16, 143-149.

Eriksen, C. W., Hamlin, R. M., \& Daye, C. The effect of flanking letters and digits on speed of identifying a letter. Bulletin of the Psychonomic Society, 1973, 2, 400-402.

Eriksen, C. W., \& Schultz, D. W. Information processing in visual search: A continuous flow conception and experimental results. Perception \& Psychophysics, 1979, 25, 249263.

Farmer, E. W., \& TAYlor, R. M. Visual search through color displays: Effects of target-background similarity and background uniformity. Perception \& Psychophysics, 1980, 27, 267-272.

FrYKLUND, I. Effects of cued-set spatial arrangement and targetbackground similarity in the partial-report paradigm. Perception \& Psychophysics, 1975, 17, 375-386.

Green, B. F., \& Anderson, L. K. Color coding in a visual 
search task. Journal of Experimental Psychology, 1956, 51, 19-24.

Harms, L., \& Bundesen, C. Color segregation and selective attention in a nonsearch task. Perception \& Psychophysics, 1983, 33, 11-19.

HitT, W. D. An evaluation of five different abstract coding methods-Experiment IV. Human Factors, 1961, 3, 120-130.

Kahneman, D. Attention and effort. Englewood Cliffs, N.J: Prentice-Hall, 1973.

Kahneman, D., \& Henik, A. Effects of visual grouping on immediate recall and selective attention. In S. Dornic (Ed.), Attention and performance VI. Hillsdale, N.J: Erlbaum, 1977.

Kahneman, D., \& Henik, A. Perceptual organization and attention. In M. Kubovy \& J. R. Pomerantz (Eds.), Perceptual organization. Hillsdale, N.J: Erlbaum, 1981.

LABERGE, D. Acquisition of automatic processing in perceptual and associative learning. In P. M. A. Rabbitt \& S. Dornic (Eds.), Attention and performance $V$. New York: Academic Press, 1975.

LABERGE, D. Automatic information processing: A review. In J. Long \& A. Baddeley (Eds.), Attention and performance $I X$. Hillsdale, N.J: Erlbaum, 1981.

Neisser, U. Cognitive psychology. New York: AppletonCentury-Crofts, 1967.

Prinzmetal, W., \& Banks, W. P. Good continuation affects visual detection. Perception \& Psychophysics, 1977, 21, 389. 395.

Schneider, W., \& Shiffrin, R. M. Controlled and automatic human information processing: 1 . Detection, search, and attention. Psychological Review, 1977, 84, 1-66.

Shiffrin, R. M., Dumais, S. T., \& Schneider, W. Characteristics of automatism. In J. Long \& A. Baddeley (Eds.), Attention and performance IX. Hillsdale, N.J: Erlbaum, 1981.

Shiffrin, R. M., \& Schneiden, W. Controlled and automatic human information processing: II. Perceptual learning, automatic attending, and a general theory. Psychological Review, 1977, 84, 127-190.

Smith, S. L. Color coding and visual search. Journal of Experimental Psychology, 1962, 64, 434-440.

Smith, S. L. Color coding and visual separability in information displays. Journal of Applied Psychology, 1963, 47, 358364.
TAYLOR, D. A. Time course of context effects. Journal of Experimental Psychology: General, 1977, 106, 404-426.

Treisman, A. Perceptual grouping and attention in visual search for features and for objects. Journal of Experimental Psychology: Human Perception and Performance, 1982, 8, 194214.

Treisman, A., \& Gelade, G. A feature-integration theory of attention. Cognitive Psychology, 1980, 12, 97-136.

Treisman, A., Sykes, M., \& Gelade, G. Selective attention and stimulus integration. In S. Dornic (Ed.), Attention and performance VI. Hillsdale, N.J: Erlbaum, 1977.

Wertheimer, M. Untersuchungen zur Lehre von der Gestalt II. Psychologische Forschung, 1923, 4, 301-350.

Williams, L. G. The effect of target specification on objects fixated during visual search. Perception \& Psychophysics, 1966, 1, 315-318.

WINER, B. J. Statistical principles in experimental design (2nd ed.). New York: McGraw-Hill, 1971.

\section{NOTE}

1. Proof. By assumptions 1 and 2,

$$
\mathrm{n}=\sum_{\mathrm{i}} \mathrm{n}_{\mathrm{i}} \text { and } \mathrm{n}_{\mathrm{s}}=\sum_{\mathbf{i}} \mathrm{n}_{\mathrm{si}} \text {, }
$$

where $n_{i}$ is the expected number of functional groups in color $i$ and $n_{s i}$ is the number of phenomenal groups. From assumption $4, n_{i}=p n_{s i}+k$, where $k$ is a constant. By assumptions 2 and 3 , if $n_{s i}=1$, then $n_{i}=1$, so $k$ must equal $1-p$. Accordingly, $n_{i}=1+p\left(n_{s i}-1\right)$. Summation over $i$ on both sides of this equation leads to Equation 2.

With $\mathrm{p}<1$, the assumptions imply that the phenomenal partition of a display was a refinement of the functional partition. A possible interpretation is that (1) the perceptual structure of a display was hierarchic, and (2) the counting task reflected the number of separate units at a lower level than that reflected by the search task.

(Manuscript received September 9, 1982; revision accepted for publication January $25,1983$. 